\title{
Relationships among adult playfulness, stress, and coping during the COVID-19 pandemic
}

\author{
Christopher Clifford ${ }^{1} \cdot$ Ellis Paulk ${ }^{1}$ - Qiyang Lin $^{2} \cdot$ Jeanne Cadwallader ${ }^{3} \cdot$ Kathy Lubbers $^{3} \cdot$ Leslie D. Frazier $^{1}$ (I)
}

Accepted: 2 February 2022

(c) The Author(s), under exclusive licence to Springer Science+Business Media, LLC, part of Springer Nature 2022

\begin{abstract}
The COVID-19 pandemic created high levels of stress that negatively affect mental health and well-being. The stress and coping process is influenced by individual difference factors, such as personality, that impact perceptual processes and emotional reactions. Adult playfulness is a personality characteristic that may lead to better mental and physical health outcomes. We test a theoretical model to determine whether the two factors of perceived stress, perceived self-efficacy (PSE) and perceived helplessness $(\mathrm{PH})$, mediate the relationship among playfulness and coping in adults $(\mathrm{N}=694)$. Scores on the Perceived Stress Scale were high indicating high levels of pandemic-related stress. The SEM model demonstrated direct effects of playfulness on PSE, PH, adaptive, maladaptive, and supportive coping. Both dimensions of perceived stress were partial mediators in the relationship among playfulness and coping outcomes. Findings illustrate the pathways by which adult playfulness can amplify or attenuate the impact of stress perceptions on coping strategies. The importance of building psychological resources such as playfulness to boost adaptive outcomes in stressful situations such as the COVID-19 pandemic is discussed.
\end{abstract}

Keywords Adulthood $\cdot$ Play $\cdot$ Playfulness $\cdot$ Stress $\cdot$ Coping

\section{Relationships among Adult Playfulness, Stress, and Coping during the COVID-19 Pandemic}

Since reaching pandemic proportions in March 2020 (World Health Organization, 2020), the SARS-CoV-2 or COVID19 pandemic has resulted in over 5.36 million deaths due to the disease and a total of 275 million confirmed cases as of December 20, 2021 (World Health Organization Coronavirus (COVID-19) Dashboard, 2021, n.d.). The overall impact of this global health crisis is unimaginable and is not confined to morbidity and mortality. At the same time, high levels of chronic stress related to the pandemic have resulted in declining mental and physical health and well-being (Brooks et al., 2020; Castelli et al., 2020; Di Giuseppe et al., 2020;

Leslie D. Frazier

frazier@fiu.edu

1 Department of Psychology, Florida International University, Miami, FL, USA

2 Department of Counseling, Educational Psychology, and Special Education, Michigan State University, East Lansing, MI, USA

3 PracticePlayfulness, Miami, FL, USA
Minahan et al., 2021; Ornell et al., 2020; Osimo et al., 2021; Rossi et al., 2020; Salari et al., 2020). These negative mental and physical outcomes are far-reaching, for example recent reports predict that the confluence of pandemic-related consequences will ultimately elevate suicide attempts and deaths in future (Zalsman et al., 2020; see also De Berardis et al., 2018; Orsolini et al., 2020). One recent meta-analysis conducted during the first peak of the pandemic showed that worldwide levels of stress were as high as $29.6 \%$ (based on 9074 participants across five studies; Salari et al., 2020). In another early study of individuals living in China, over $8 \%$ reported moderate to severe stress (Wang et al., 2020). Whereas in Italy, $27.2 \%$ of the population self-reported high or extremely high levels of stress (Mazza et al., 2020). In the nearly two years since the pandemic the prolonged stress associated with this global health crisis continues to impact mortality, mental and physical health outcomes, and quality of life worldwide (Liu et al., 2021).

The experience of stress and how we cope with it is influenced by individual difference factors such as personality. Personality impacts individuals' perceptual processes and emotional reactions to the stress of the pandemic (Osimo et al., 2021). Personality also influences how individuals cope with stress. Within the context of the pandemic, those 
with higher levels of resilience coped more successfully with pandemic-related stressors (Morales-Vives et al., 2020). One personality characteristic that may impact the stress and coping process is playfulness (Guitard et al., 2005; Proyer, 2013). Like resilience and optimism and other positive psychological attributes, adult playfulness could be a resource that leads to better mental and physical health outcomes (Farley et al., 2021; Proyer et al., 2018), especially important in the extraordinary context of coping with the COVID-19 pandemic. The present study examines the potentially beneficial role of adult playfulness as it impacts perceived stress and coping during the COVID-19 pandemic.

\section{Perceived Stress}

The subjective experience of stress is based upon a cognitive appraisal process through which (a) the event is assessed as threatening or demanding (e.g., primary appraisal), and (b) one's resources for managing are seen as lacking (e.g., secondary appraisal; Lazarus \& Folkman, 1984). Since the cognitive appraisal process is driven by an individual's unique perceptions, interpretations, and experiences with a particular stressor, there are large individual differences in the perception of stress.

The most widely used measure of perceived stress is the Perceived Stress Scale (PSS) developed by Cohen and colleagues (Cohen et al., 1983). The PSS assesses the degree to which individuals perceive their lives as stressful over the last month. Several scholars (Golden-Kreutz et al., 2004; Hewitt et al., 1992; Khalili et al., 2017; Örücü \& Demir, 2009; Roberti et al., 2006) have suggested a two-factor structure for the PSS: (a) perceived self-efficacy (the ability to manage and control the stressor); and (b) perceived helplessness (the perception that stress is outside one's control). Studies show that perceived self-efficacy relates to lower stress perceptions and better mental and physical health outcomes, whereas, perceived helplessness shows the opposite pattern (Durak et al., 2010; Kaya et al., 2019). Understanding the individual difference factors that may impact the perceptual and subjective experience of stress is important and can shed light on how people cope.

\section{Coping}

Coping is conceptualized as the "cognitive and behavioral efforts to manage specific external and/or internal demands that are appraised as taxing or exceeding the resources of the person" (Lazarus \& Folkman, 1984, p. 34). It represents the efforts individuals make to manage or adjust to the demands of the stressful situation as well as to regulate the emotional response to it (Barreto \& Frazier, 2012).

Just as there are individual differences in the perception of stress, there are also individual differences in how individuals cope in different contexts (Carver et al., 1989). Coping aimed at directly altering the situation represents a form of problem-focused, planful problem-solving or active coping (Folkman \& Lazarus, 1980), and is useful when the individual has a high degree of perceived control and the self-efficacy to change the situation. Emotion-focused coping involves regulation of emotions through strategies such as distancing, venting, searching for meaning. Its aim is to change the emotional impact of the stressor without actually changing the situation (Frazier, 2002). Therefore, emotion-focused coping is useful when the individual has a relatively low amount of perceived control over the situation (Lazarus, 1993). Both problem-focused and emotionfocused coping are often used simultaneously (Folkman \& Lazarus, 1980).

Within health contexts, research on coping attempts to capture the more fine-grained strategies used to cope with stress (Carver et al., 1989). Specifically, disengagement, self-distraction, active coping, using emotional support from intimate partners, emotional support from others, relying on religion, humor, and substance use were found to represent meaningful coping strategies for managing illness (Fillion et al., 2002). Some researchers (e.g., Brown et al., 2005; Folkman \& Lazarus, 1988; Jex et al., 2001) have argued that it is more useful to distinguish coping efforts based on whether they are harmful (e.g., ineffective, not reducing or increasing distress) or helpful (e.g., effective, reducing or ameliorating distress). Coping strategies that promote better adjustment are conceptualized as adaptive coping to refer to efforts to deal directly with the stressor by finding and implementing solutions (Parasuraman \& Hansen, 1987). Whereas maladaptive coping refers to coping through avoidance, self-criticism, and negative emotions (Kirby et al., 2011). Typically, adaptive coping leads to positive outcomes and maladaptive coping leads to negative outcomes (Parasuraman \& Hansen, 1987). This distinction could be particularly useful in health contexts.

Coping with the stress of the COVID-19 pandemic has been universally challenging. Research shows that in addition to extremely high levels of stress and experiences of PTSD, individuals who reported they avoided thinking about the stress and those who were unsure or unable to cope with it had greater levels of anxiety and depression (Kar et al., 2021). In one study of healthcare professionals during the pandemic, positive attitude - a functional coping strategy -- as well as turning to religion were adaptive and lead to better outcomes (Kar et al., 2021). Seeking social support and avoidance in a were coping strategies that led to negative outcomes such as higher distress (Babore et al., 2021). 
Avoidance and denial have traditionally been found to be dysfunctional ways to manage stress, especially in contexts such as a pandemic (Babore et al., 2021; Phua, 2005; Teasdale et al., 2012). These findings highlight the role of individual differences in the appraisal of stress and the situational conditions that impact coping efficacy (Biggs et al., 2017; Folkman \& Moskowitz, 2004; Lazarus \& Folkman, 1984).

\section{Personality and the Stress Process}

Personality, the lens through which we interpret our world, drives the individual differences seen in the stress and coping processes (Barreto \& Frazier, 2012). Individuals assign meaning to a given situation through a dynamic, interactive, constructive process in which personality plays a key role in shaping emotional reactions, coping responses, and even one's health (Hooker et al., 1998; Lazarus, 1991). Personality may have direct effects on stress, coping, and health and can predispose people to interpret events in benign or threatening ways. Personality also impacts the stress process indirectly through its relationship with resources brought to bear in the coping process. Frazier and colleagues (Frazier, 2000; Hooker et al., 1994; Hooker et al., 1998), showed that personality is a powerful predictor of coping patterns and mental and physical health outcomes.

Positive personality characteristics may attenuate the experience of stress and lead to better coping outcomes (Carver \& Scheier, 1991). For example, people who have positive expectations and optimism, may perceive less stress and cope better with stressful life events (Carver \& Scheier, 1991). Personality predispositions, such as optimism, may represent the ability to remain flexible and may be key to resilience and thriving in extremely stressful situations (Carver, 1998). Due to the overlap between the traits that predict resilience and those that define playfulness, such evidence potentiates playfulness as an effective means to promote resilience and even thriving within the COVID19 pandemic. Personality may also impact coping through social support (Cohen \& Wills, 1985). The stress-buffering effects of interpersonal relationships may depend on an individual's personality. A playful person may elicit more social support, which may then, be an effective moderator of the stress process.

\section{Playfulness as a Dimension of Personality}

The concept of playfulness has been studied extensively in childhood. However, until recently, it has been largely overlooked in adulthood (Proyer, 2017; Sutton-Smith, 1966). In adulthood playfulness is conceptualized as an individual difference variable that predisposes the way a person perceives or experiences situations (Proyer, 2012, 2017; Proyer et al., 2018). As Barnett states, playfulness is "the predisposition to frame (or reframe) a situation in such a way as to provide oneself (and possibly others) with amusement, humor, and/or entertainment" (Barnett, 2007, p. 955).

Research has advanced understanding of the importance of adult playfulness (Bowman, 1987; Glynn, 1992; Guitard et al., 2005; Martocchio \& Webster, 1992), and demonstrated its benefit for better health, higher productivity, tension release, group cohesion, and improved workplace performance (Shen et al., 2014). Further research has linked adult playfulness to higher levels of creativity (Tegano, 1990), improved morale and motivation (Lyons, 1987), and increased adaptivity (Guitard et al., 2005).

\section{Playfulness and Coping}

Playfulness has been argued to be crucial to the process of coping (Chang et al., 2013; Hess \& Bundy, 2003; Magnuson \& Barnett, 2013; Saunders et al., 1999; Staempfli, 2007; Yarnal, 2011). As Magnuson and Barnett (2013) showed, playfulness mediates the stress-coping process through its influence on cognitive appraisal. As a coping strategy, playfulness may mediate the interpretation and experience of stress (Hess \& Bundy, 2003; Staempfli, 2007). Playfulness may also guide reframing stressful situations in a way that facilitates flexibility, reduces perceived stress, and improves resilience (Barnett, 2007). In addition, highly playful individuals use adaptive or engagement coping strategies more frequently than their less playful counterparts, although both groups used the same types of coping strategies overall (Magnuson \& Barnett, 2013). Higher levels of playfulness result in greater flexibility when dealing with difficult life events (Bundy, 1993), supporting the notion that playfulness acts as a facilitator of stress and coping in adults (Qian \& Yarnal, 2011). These findings suggest that playfulness may serve as an important coping resource that affords individuals with the capacity to cope more effectively with highly stressful situations than may otherwise cause psychological distress.

\section{Coping with the Stress of the Pandemic}

Consider the stress of the COVID-19 pandemic. The stressors of the pandemic, while universal, dynamic, and unfolding over time, still impacts individuals differently leading to interindividual differences in how people cope with the stress of COVID-19. It bears mention that anxiety and distress are normal reactions to the unpredictable, ambiguous, and personally-threatening nature of the COVID-19 
pandemic. Nevertheless, ineffective coping may be maladaptive and may worsen negative mental and physical health outcomes. Whereas effective coping strategies are critical to mitigating the negative mental and physical health outcomes that have arisen due to the pandemic. Research has shown that playfulness acts as an effective facilitator in the stress process by reducing perceived stress, encouraging adaptive coping, decreasing negative emotions, and increasing positive emotions and life satisfaction. Despite their elevated risk of illness and death due to COVID-19, adults, and especially older adults, reported lower levels of negative affect and more agentic coping than younger adults (Young et al., 2021). Considering the benefits conveyed through playfulness, its use during the COVID-19 pandemic could prove to be an important, and even vital, resource to mitigate negative mental health outcomes.

\section{The Present Study}

The purpose of the present study was to examine the attributes of playfulness in adults and how they may interact with stress and coping within the context of the COVID-19 pandemic. Our goals were to determine what aspects of playfulness were most characteristic of our sample and to determine how playfulness impacts the perception of stress and the choice of coping strategy. Given the influence of playfulness on the cognitive appraisal process, we were specifically interested in the two-factor model of perceived stress (Durak et al., 2010; Kaya et al., 2019). The overarching goal is to identify a pattern of playfulness in adulthood that may serve as a valuable resource for effective stress management, especially in times of extreme stress. To achieve this goal, we test a theoretically grounded model (see Fig. 1) in which the two-factor model of perceived stress mediates the influence of playfulness on coping outcomes.

Consistent with earlier research (Chang et al., 2013; Magnuson \& Barnett, 2013; Staempfli, 2007), we hypothesized that playful adults would experience less stress and cope more effectively with the stress of COVID-19. We expected playfulness to coact with perceived stress to either amplify or attenuate coping.

\section{Methods}

\section{Participants}

The participants in this study were 837 English-speaking adults $\left(M_{\mathrm{age}}=23.52, S D=6.28\right)$. The sample was predominantly female $(88.05 \%)$. The sample self-reported race/ ethnicity as African American/Black (13.52\%), Asian American/Pacific Islander (1.33\%), Asian (1.21\%), Biracial/ multiracial (1.70\%), Hispanic/Latino (67.36\%), Middle Eastern/Arab (0.73\%), Native American/native Alaskan (0.12\%), White/European American (8.40\%), and other (5.6\%). Whereas the most recent U.S. census shows that $18 \%$ of the population reports Hispanic as their racial/ethnic background, this study was conducted at the largest U.S. Hispanic-serving university in the nation. The largely Hispanic student body is representative of the population in which this research took place. Socioeconomic status was measured on a Likert-type scale that ranged from an annual household income of less than $\$ 4000$ to a high of over $\$ 150,000$ or more. The most frequently self-reported annual income categories were $\$ 20,000-\$ 34,000$ and $\$ 35,000-\$ 49,000$. This is lower than the U. S. Department of Household and Labor statistics national median family income for 2021 that was $\$ 79,000$ (Richardson, 2021).

\section{Measures}

\section{Playfulness}

Playfulness was measured using the Short Measure of Adult Playfulness (SMAP; Proyer, 2012), a five-item questionnaire using a four-point Likert-type scale with answer choices ranging from 1 (strongly disagree) to 4 (strongly agree). Questions ask participants to self-assess how playful they
Fig. 1 Mediation model displaying direct and indirect pathways of playfulness, perceived self-efficacy, perceived helplessness, and coping dimensions

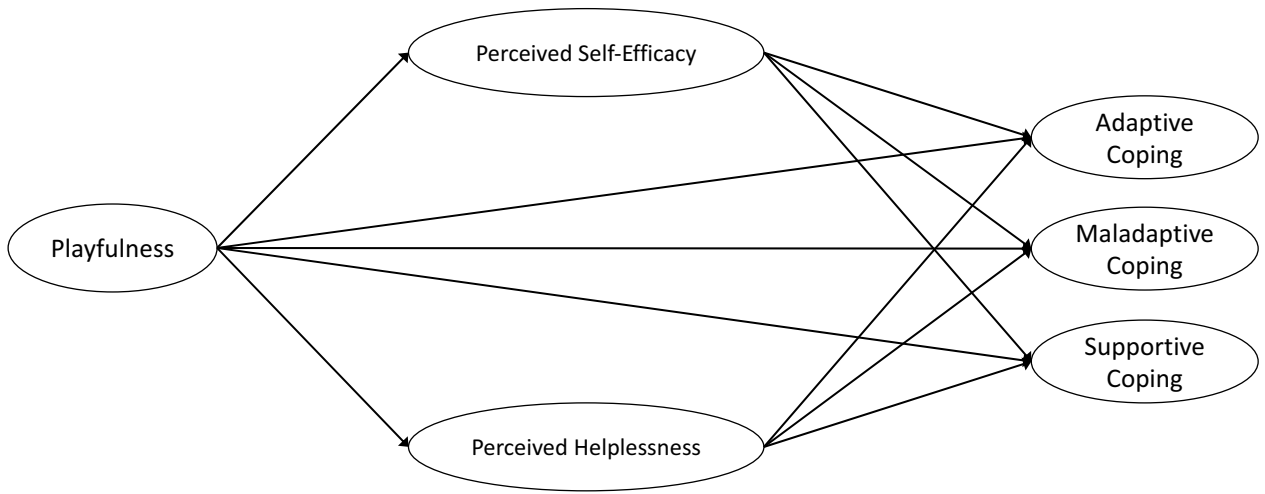


are both as identified by themselves ("I am a playful person"), and by others ("Good friends would describe me as a playful person"), as well as the frequency and level of engagement they normally experience involving play. High scores indicate greater playfulness. In the present sample, scores ranged from a low of five to a high of $20(M=15.76$; $S D=2.92)$. The Cronbach's alpha $(a=0.84)$ indicated strong internal consistency and reliability.

\section{Stress}

The Perceived Stress Scale (PSS; Cohen et al., 1983) is a 10-item Likert-type scale that assesses the perception of stress during the last month, and how often respondents thought or felt a certain way. Answer choices range from 0 (never) to 4 (very often). Questions such as "In the last month, how often have you felt nervous and 'stressed'?" or "In the last month, how often have you felt that you were on top of things?" After item reversals a total score is gleaned. High scores indicate higher perceptions of stress. Consistent with prior research, we conducted a confirmatory factor analysis (CFA; Lance \& Vandenberg, 2002) and landed on two distinct factors: perceived helplessness and perceived self-efficacy. In the present sample, scores ranged from a low of one to a high of $40(M=20.08 ; S D=7.42)$. The Cronbach's alpha $(\alpha=0.88)$ for the total score in the current sample indicates strong internal consistency and reliability.

\section{Coping}

Coping strategies were assessed using 28-item brief COPE scale (Carver, 1997). Coping is assessed across 14 dimensions: active coping, planning, positive reframing, acceptance, humor, religion, using emotional support, using instrumental support, self-distraction, denial, venting, substance use, behavioral disengagement, and self-blame. Responses, on a Likert-type scale, ranged from 1 ("I haven't been doing this at all") to 4 ("I've been doing this a lot"). We conducted confirmatory factor analysis (CFA; Lance \& Vandenberg, 2002) to assess the factor structure of the brief COPE scale in the present sample. We found coping strategies cluster onto three distinct variables: adaptive coping focused (e.g., strategies that emphasized active engagement and planning); maladaptive coping (e.g., strategies focused on disengaging from a problem or distracting oneself including denial, disengagement, substance use); and supportive coping (e.g., focused on receiving support from other including emotional support, religion). In the present sample, the Cronbach's alpha $(\alpha=.86)$ for the total scale demonstrated strong internal consistency and high reliability.

\section{Procedure}

Recruitment took place through online SONA systems software of a large public urban university in the southern United States. SONA systems is an online system for announcing, scheduling, and awarding research credit for university students who participate in research. Additionally, we recruited through social media platforms where flyers were posted. All recruitment channels provided inclusion/ exclusion criteria required for participation. Inclusion criteria were: (a) age 18 years old or older; and (b) competence reading and writing in English. Participants who did not meet these criteria were excluded from participation in the prescreening questions in SONA systems and within the survey itself. After providing informed consent, participants were administered the scales as part of a larger study on the mental and physical health outcomes during the COVID-19 pandemic. The survey was administered fully online through Qualtrics survey software. Participants recruited through the University were awarded research credit for participation.

\section{Results}

A total score of 13 on the PSS represents a normal level of stress and scores of 20 or higher represent high levels of stress which require therapeutic intervention (Cohen \& Williamson, 1988). Mean scores on the PSS across many studies with many samples range from 12 to 14.7 (Lee, 2012). The average score for the present sample was $20.08(S D=7.42)$. Given that respondents indicated their perceptions of stress over the last month, during the pandemic, these high levels of stress reflect the stress of the pandemic.

The data set did not have a significant amount of missing data. Outliers were minimal due to the Likert-type data collected. The analyses were performed on ordinal categorical data, thus missing data techniques such as FIML were not used, and missing cases were dropped resulting in a total of 694 participants. We opted to use the Lavaan Package (Roseel, 2012) in R (Bunn et al, 2016) for the Structural Equation Modeling (SEM) on our ordered categorical data.

Based on prior research (Ng, 2013) and CFA results confirming overall model fit, the PSS was treated as two latent variables: perceived helplessness and perceived self-efficacy. Next, we ran a parallel mediation model (See Fig. 1) with two mediators computing both the direct and indirect pathways using Lavaan (Rosseel, 2012) in R (Bunn et al., 2016). The final fit indices showed the model had an acceptable fit for the variables $\left(\chi^{2}(764)\right.$ sig $:<0.001$, TLI -0.91 , CFI - 0.91, RMSEA - 0.08, SRMR - 0.10). See Fig. 1. 


\section{The Model}

The SEM model results showed playfulness was a significant predictor of perceived self-efficacy $(\beta=0.315, p<0.001)$, and perceived helplessness $(\beta=-0.141, p=0.001)$. Higher levels of playfulness were related to higher levels of perceived self-efficacy while higher levels of playfulness were related to lower levels of perceived helplessness. The specifics of these and further comparisons in the main model can be found in SEM regression estimates on Table 1.

Perceived self-efficacy was a significant predictor of adaptive coping ( $\beta=0.585, p<0.001$ ), maladaptive coping $(\beta=-0.127, p=0.017)$, and supportive coping $(\beta=0.319$, $p<0.001)$. Increases in self-efficacy showed increases for adaptive and supportive coping. However, increasing selfefficacy decreased maladaptive coping. Perceived helplessness similarly had significant relations between all three styles of coping: adaptive ( $\beta=0.336, p=0.001)$, maladaptive $(\beta=0.581, p<0.001)$, and supportive $(\beta=0.377, p<0.001)$.
Increases in perceived helplessness showed across the board increases in each of the three styles of coping.

Examining the total indirect pathways for mediation, the pathway of playfulness through perceived self-efficacy was significant for adaptive $(\beta=0.184, p<0.001)$, maladaptive ( $\beta=-0.040, p=0.021)$, and supportive coping $(\beta=0.119$, $p<0.001)$. Increases in playfulness predicted increases in adaptive and supportive coping through perceived selfefficacy. In contrast, increases in playfulness predicted a decrease in maladaptive coping when it was through selfefficacy. For the indirect pathway examining how playfulness predicted coping through perceived helplessness the adaptive $(\beta=-0.051, p=0.003)$, maladaptive $(\beta=-0.082$, $p=0.001)$, and supportive coping $(\beta=-0.045, p=0.003)$ indirect paths were once again all significant. For the indirect pathway using the perceived helplessness mediator, all three coping outcomes showed that an increase in playfulness would predict a decrease in coping along perceived helplessness.
Table 1 SEM regression estimates table

\begin{tabular}{|c|c|c|c|c|c|c|}
\hline \multirow[t]{2}{*}{ Parameter Estimates } & \multirow[t]{2}{*}{ Estimate } & \multirow{2}{*}{$\begin{array}{l}\text { Standardized } \\
\text { Estimate }(\beta)\end{array}$} & \multirow[t]{2}{*}{$S E$} & \multicolumn{2}{|l|}{$95 \% C I$} & \multirow[t]{2}{*}{$p$} \\
\hline & & & & $L B$ & $U B$ & \\
\hline \multicolumn{7}{|l|}{ Direct Effects of Playfulness } \\
\hline Adaptive Coping & 0.177 & 0.277 & 0.025 & 0.129 & 0.226 & $<0.001$ \\
\hline Maladaptive Coping & 0.046 & 0.116 & 0.014 & 0.02 & 0.073 & 0.001 \\
\hline Supportive Coping & 0.132 & 0.175 & 0.03 & 0.073 & 0.191 & $<0.001$ \\
\hline Perceived Self-Efficacy & 0.242 & 0.315 & 0.032 & 0.179 & 0.306 & $<0.001$ \\
\hline Perceived Helplessness & -0.116 & -0.141 & 0.033 & -0.182 & -0.05 & 0.001 \\
\hline \multicolumn{7}{|l|}{ Mediator Effects } \\
\hline \multicolumn{7}{|c|}{ Perceived Self-Efficacy predicting } \\
\hline Adaptive Coping & 0.485 & 0.585 & 0.055 & 0.378 & 0.593 & $<0.001$ \\
\hline Maladaptive Coping & -0.066 & -0.127 & 0.027 & -0.119 & -0.012 & 0.017 \\
\hline Supportive Coping & 0.37 & 0.377 & 0.054 & 0.263 & 0.476 & $<0.001$ \\
\hline \multicolumn{7}{|c|}{ Perceived Helplessness predicting } \\
\hline Adaptive Coping & 0.284 & 0.366 & 0.045 & 0.195 & 0.372 & $<0.001$ \\
\hline Maladaptive Coping & 0.28 & 0.581 & 0.038 & 0.206 & 0.353 & $<0.001$ \\
\hline Supportive Coping & 0.292 & 0.319 & 0.048 & 0.199 & 0.385 & $<0.001$ \\
\hline \multicolumn{7}{|l|}{ Indirect Effects } \\
\hline \multicolumn{7}{|c|}{ Playfulness through Perceived Self-Efficacy } \\
\hline Adaptive Coping & 0.118 & 0.184 & 0.02 & 0.078 & 0.157 & $<0.001$ \\
\hline Maladaptive Coping & -0.016 & -0.04 & 0.007 & -0.029 & -0.002 & 0.021 \\
\hline Supportive Coping & 0.09 & 0.119 & 0.017 & 0.056 & 0.123 & $<0.001$ \\
\hline \multicolumn{7}{|c|}{ Playfulness through Perceived Helplessness } \\
\hline Adaptive Coping & -0.033 & -0.051 & 0.011 & -0.055 & -0.011 & 0.003 \\
\hline Maladaptive Coping & -0.032 & -0.082 & 0.01 & -0.052 & -0.013 & 0.001 \\
\hline Supportive Coping & -0.034 & -0.045 & 0.012 & -0.057 & -0.011 & 0.003 \\
\hline \multicolumn{7}{|l|}{ Total Effects of Playfulness } \\
\hline Adaptive Coping & 0.262 & 0.41 & 0.024 & 0.216 & 0.308 & $<0.001$ \\
\hline Maladaptive Coping & -0.002 & -0.005 & 0.016 & -0.033 & 0.028 & 0.894 \\
\hline Supportive Coping & 0.187 & 0.248 & 0.028 & 0.133 & 0.242 & $<0.001$ \\
\hline
\end{tabular}


Finally, the direct effects of playfulness on coping showed significant results for the three coping styles: adaptive $(\beta=0.277, p<0.001)$, maladaptive $(\beta=0.116, p=0.001)$ and supportive $(\beta=0.175, p<0.001)$. Higher levels of playfulness were directly related to higher levels of adaptive coping, higher levels of maladaptive coping and higher levels of supportive coping. The total effects pathways were significant in the case of adaptive $(\beta=0.410, p<0.001)$ and supportive coping ( $\beta=0.248, p<0.001$ ) but not significant in the case of maladaptive coping $(\beta=-0.005, p=0.894)$.

Due to the results showing maladaptive coping not having a significant total effect, an additional examination of the mediators was run by comparing the results of single-mediator models. In these models, perceived self-efficacy and perceived helplessness were each given their own model where they were used as the sole mediator in the play-stress-coping mediation model. These results can be seen in Appendix: Supplemental Tables 1A and 1B.

Of note, these single mediation models show the total effects of maladaptive coping being insignificant in both cases. The only notable difference in the single mediator models was with perceived helplessness, where the indirect effects of playfulness through both adaptive and supportive coping were insignificant. This may indicate that perceived self-efficacy has a confounding effect on perceived helplessness as a mediator (MacKinnon et al., 2000).

In summary, playfulness predicted adaptative and supportive coping completely, both through the direct, indirect, and total effects. Increases in playfulness positively predicted adaptive and supportive coping directly as well as indirectly through perceived self-efficacy. Higher levels of playfulness were related to lower levels of adaptive and supportive coping through perceived helplessness. Finally, playfulness predicted maladaptive coping through direct effects and through the indirect effects of perceived self-efficacy and perceived helplessness. Higher playfulness linked to higher maladaptive coping directly but lower maladaptive coping through perceived self-efficacy and perceived helplessness. Further, playfulness was a significant predictor for both perceived self-efficacy and perceived helplessness; a positive predictor in the case of self-efficacy and a negative predictor in the case of perceived helplessness.

\section{Discussion}

This study demonstrates how playfulness predicts stress and coping in adults during the COVID-19 pandemic. Our findings show that, in the context of the pandemic, our participants were highly stressed. Playful individuals -- those who consider themselves playful and are identified as such by others -- perceive less stress and use more adaptive coping strategies to lessen the distress. Specifically, playfulness, a beneficial psychological resource, related to perceived stress in predictable ways. Higher levels of playfulness were positively related to higher levels of perceived self-efficacy for stress. Lower levels of playfulness related to higher levels of perceived helplessness. Playfulness, defined as the predisposition to perceive and interpret situations in a way that provides oneself and others with amusement, humor, and/or entertainment (Proyer \& Ruch, 2011), is linked with how stressful situations are perceived as either something within or outside one's control. Our findings support prior research that shows that playfulness reduces stress (Magnuson \& Barnett, 2013). Our findings also show that more playful people are more likely to use adaptive and social support coping - both effective means at reducing distress. We also found the opposite pattern in which lower levels of playfulness related to higher levels of maladaptive coping. These findings are consistent with prior research that shows that playful individuals tend to use beneficial, adaptive, and stressor-focused coping strategies while less playful individuals tend to rely on negative, avoidant, escape-oriented, maladaptive strategies (Magnuson \& Barnett, 2013). Our findings suggest that especially in the high stress context of the COVID-19 pandemic, playfulness can be a personal resource that provides a strong adaptive advantage for stress perception and coping efficacy.

In this study we have extended prior research to examine the role of playfulness in stress and coping at a more detailed level by examining the two factors of perceived stress, and how those perceptions may mediate the role of playfulness on coping. We found direct effects of playfulness on both dimensions of perceived stress, and all dimensions of coping. As well, both dimensions of perceived stress showed direct effects on each of the coping outcomes. Perceived self-efficacy was related to higher levels of adaptive and support coping and lower levels of maladaptive coping. Whereas higher levels of perceived helplessness were related to lower adaptive and support coping and higher maladaptive coping. We found that perceived self-efficacy partially mediates the impact of playfulness on all three forms of coping. That is, the coactive influence of higher playfulness and higher self-efficacy is positively related to more adaptive and support coping, and reduces the likelihood of maladaptive coping. We also found that perceived helplessness partially mediates the role of playfulness such that the positive impacts of playfulness on adaptive coping remain, and the negative impact of perceived helplessness on adaptive coping are offset. Similarly, the interactive effects of playfulness and perceived helplessness relate to lower levels of maladaptive coping.

Some may see our reliance on cross-sectional data to test our mediational hypotheses as a potential limitation. One could certainly argue that by modeling the manner in which relationships among variables unfold over time, longitudinal 
mediation designs (Maxwell et al., 2011; Maxwell \& Cole, 2007), may be better equipped than crosssectional designs to speak to causality and causal ordering. However, it bears emphasizing that the temporal precedence captured by these models is a necessary, but not a sufficient, condition for establishing causality. In the context of our present research questions, we set out to conduct a broad assessment of the influence of playfulness on perceived stress and coping. We assessed these individual differences factors using participants' responses to standard, well-validated, widely-used scales. Therefore, rather than viewing our design as a convenient, possibly distorted (cf. Maxwell et al., 2011; Maxwell \& Cole, 2007) cross-sectional substitute for an ostensibly superior longitudinal one, we, in fact, believe this to be a valid, defensible, appropriate design for answering our specific research questions. Other possible limitations are the self-report nature of the data and the reliance on a university participant pool. Nevertheless, the large sample size and extensive analyses validated the measures and provided illuminating pathways that may provide blueprints for future larger population-based, longitudinal, or intervention-type studies.

Bolger (1990) said that "coping is personality in action under stress" (p. 525). In the present study we have shown that playfulness, a disposition that influence how individuals perceive, interpret, and engage with their lives, has both direct and indirect effects on coping - and therefore may be an important malleable personal resource that can be cultivated to help people perceive less stress, perceive more control over the stress they have, and to use more adaptive coping strategies to reduce the distress. Although we have measured playfulness in terms of how people currently see themselves, and we have shown how those self-perceptions are beneficial in the stress-coping process, playfulness can be learned at any age (Andreopoulou \& Moustakas, 2019; McMillan, 2017; Rice, 2009; Tanis, 2012). There are many ways to be playful from engaging with ideas, being spontaneous, lightening the mood with humor or silliness, playing games, to framing a situation in a positive light; playfulness provides an adaptive benefit that leads to better outcomes for mental and physical well-being (Proyer, 2017). Our findings demonstrate the importance of perceiving self-efficacy for managing stress as a direct and indirect influence on coping. The combination of playfulness and perceive self-efficacy interact to positively bolster adaptive and supportive coping strategies. The take home messages from our findings are the potential useful pathways through which adults can maximize their playfulness to achieve more optimal outcomes even within the highly stressful context of the COVID-19 pandemic.
Supplementary Information The online version contains supplementary material available at https://doi.org/10.1007/s12144-022-02870-0.

\section{Declarations}

The data presented in this manuscript are available upon reasonable request.

Conflict of Interest We have no known conflicts of interest to disclose.

\section{References}

Andreopoulou, P., \& Moustakas, L. (2019). Playful learning and skills improvement. Open Journal for Educational Research, $3(1), 25-38$

Babore, A., Trumello, C., Lombardi, L., Candelori, C., Chirumbolo, A., Cattelino, E., Baiocco, R., Bramanti, S. M., Viceconti, M. L., Pignataro, S., \& Morelli, M. (2021). Mothers' and Children's mental health during the COVID-19 pandemic lockdown: The mediating role of parenting stress. Child Psychiatry \& Human Development, 1-13.

Barnett, L. A. (2007). The Nature of Playfulness in Young Adults. Personality and Individual Differences, 43(4), 949-958.

Barreto, M., \& Frazier, D. L. (2012). Coping with life events through possible selves. Journal of Applied Social Psychology, 42(7), 1785-1810. https://doi.org/10.1111/j.1559-1816.2012.00918.x

Biggs, A., Brough, P., \& Drummond, S. (2017). Lazarus and Folkman's psychological stress and coping theory. In C. L. Copper \& J. C. Quick (Eds.), The handbook of stress and health: A guide to research and practice. Wiley.

Bolger, N. (1990). Coping as a personality process: A prospective study. Journal of Personality and Social Psychology, 59(3), 525.

Bowman, J. (1987). Making Work Play. In G. A. Fine (Ed.), Meaningful play, playful meanings (pp. 61-71). Human Kinetics.

Brooks, S. K., Webster, R. K., Smith, L. E., Woodland, L., Wessely, S., Greenberg, N., \& Rubin, G. J. (2020). The psychological impact of quarantine and how to reduce it: Rapid review of the evidence. The Lancet, 395(10227), 912-920.

Brown, S. P., Westbrook, R. A., \& Challagalla, G. (2005). Good cope, bad cope: Adaptive and maladaptive coping strategies following a critical negative work event. Journal of Applied Psychology, 90(4), 792.

Bundy, A. (1993). Assessment of play and leisure: Delineation of the problem. American Journal of Occupational Therapy, 47, 217-222.

Bunn, A., Korpela, M., Biondi, F., Campelo, F., Mérian, P., Qeadan, F., \& Zang, C. (2016). dplR: Dendrochronology program library in R, v 1.6. 4.

Carver, C. S. (1997). You want to measure coping but your protocol's too long: Consider the brief cope. International Journal of Behavioral Medicine, 4(1), 92-100. https://doi.org/10.1207/ s15327558ijbm0401_6

Carver, C. (1998). Resilience and thriving: Issues, models, and linkages. Society for the Psychological Study of Social Issues, 54(2), 245-266.

Carver, C. S., \& Scheier, M. F. (1991). Self-regulation and the self. In The self: Interdisciplinary approaches (pp. 168-207). Springer.

Carver, C. S., Scheier, M. F., \& Weintraub, J. K. (1989). Assessing coping strategies: A theoretically based approach. Journal of Personality and Social Psychology, 56(2), 267-283. https://doi. org/10.1037/0022-3514.56.2.267

Castelli, L., Di Tella, M., Benfante, A., \& Romeo, A. (2020). The spread of COVID-19 in the Italian population: Anxiety, 
depression, and post-traumatic stress symptoms. Canadian Journal of Psychiatry. Revue Canadienne de Psychiatrie, 65(10), 731.

Chang, P.-J., Qian, X., \& Yarnal, C. (2013). Using playfulness to cope with psychological stress: Taking into account both positive and negative emotions. International Journal of Play, 2(3), 273-296. https://doi.org/10.1080/21594937.2013.855414

Cohen, S., \& Williamson, G. (1988). Perceived stress in a probability sample of the United States. In S. Spacapan \& S. Oskamp (Eds.), The social psychology of health: Claremont symposium on applied social psychology (pp. 31-67). Sage.

Cohen, S., \& Wills, T. A. (1985). Stress, social support, and the buffering hypothesis. Psychological Bulletin, 98(2), 310.

Cohen, S., Kamarck, T., \& Mermelstein, R. (1983). Perceived stress scale (PSS): A global measure of perceived stress. Journal of Health and Social Behavior, 24, 385-396.

De Berardis, D., Fornaro, M., Valchera, A., Cavuto, M., Perna, G., Di Nicola, M., ... Tomasetti, C. (2018). Eradicating suicide at its roots: preclinical bases and clinical evidence of the efficacy of ketamine in the treatment of suicidal behaviors. International Journal of Molecular Sciences, 19(10), 2888.

Di Giuseppe, M., Zilcha-Mano, S., Prout, T. A., Perry, J. C., Orrù, G., \& Conversano. C. (2020). Psychological impact of coronavirus disease 2019 among Italians during the first week of lockdown. Frontiers in Psychiatry, 11, 1022.

Durak, M., Senol-Durak, E., \& Gencoz, T. (2010). Psychometric properties of the satisfaction with life scale among Turkish university students, correctional officers, and elderly adults. Social Indicators Research, 99, 413-429.

Farley, A., Kennedy-Behr, A., \& Brown, T. (2021). An investigation into the relationship between playfulness and well-being in Australian adults: An exploratory study. OTJR: Occupation, Participation and Health, 41(1), 56-64.

Fillion, L., Kovacs, A. H., Gagnon, P., \& Endler, N. S. (2002). Validation of the shortened cope for use with breast cancer patients undergoing radiation therapy. Current Psychology, 21(1), 17-34. https://doi.org/10.1007/bf02903157

Folkman, S. F. \& Lazarus, R. S. (1980). An analysis of coping in a middle-aged community sample. Journal of Health and Social Behavior, 21, 219-239.

Folkman, S., \& Lazarus, R. S. (1988). The relationship between coping and emotion: Implications for theory and research. Social Science \& Medicine, 26(3), 309-317.

Folkman, S., \& Moskowitz, J. T. (2004). Coping: Pitfalls and promise. Annual Review of Psychology, 55(1), 745-774. https://doi.org/10. 1146/annurev.psych.55.090902.141456

Frazier, L. D. (2000). Coping with disease-related stressors in Parkinson's disease. The Gerontologist, 40(1), 53-63. https://doi.org/10. 1093/geront/40.1.53

Frazier, L. D. (2002). Stability and change in patterns of coping with Parkinson's disease. The International Journal of Aging and Human Development, 55(3), 207-231.

Glynn, M. A. (1992). The adult playfulness scale: An initial assessment. Psychological Reports, 71(5), 83. https://doi.org/10.2466/ pr0.71.5.83-103

Golden-Kreutz, D. M., Browne, M. W., Frierson, G. M., \& Andersen, B. L. (2004). Assessing stress in cancer patients: A second-order factor analysis model for the perceived stress scale. Assessment, 11(3), 216-223.

Guitard, P., Ferland, F., \& Dutil, É. (2005). Toward a better understanding of playfulness in adults. OTJR: Occupation, Participation and Health, 25(1), 9-22. https://doi.org/10.1177/153944920502500 103

Hess, L. M., \& Bundy, A. C. (2003). The association between playfulness and coping in adolescents. Physical \& Occupational Therapy in Pediatrics, 23(2), 5-17. https://doi.org/10.1080/j006v23n02_02
Hewitt, P. L., Flett, G. L., \& Mosher, S. W. (1992). The Perceived Stress Scale: Factor structure and relation to depression symptoms in a psychiatric sample. Journal of Psychopathology and Behavioral Assessment, 14(3), 247-257.

Hooker, K., Frazier, L. D., \& Monahan, D. J. (1994). Personality and coping among caregivers of spouses with dementia. The Gerontologist, 34(3), 386-392.

Hooker, K., Monahan, D. J., Bowman, S. R., Frazier, L. D., \& Shifren, K. (1998). Personality counts for a lot: Predictors of mental and physical health of spouse caregivers in two disease groups. The Journals of Gerontology Series B: Psychological Sciences and Social Sciences, 53(2), P73-P85.

Jex, S. M., Bliese, P. D., Buzzell, S., \& Primeau, J. (2001). The impact of self-efficacy on stressor-strain relations: Coping style as an explanatory mechanism. Journal of Applied Psychology, 86(3), 401.

Kar, N., Kar, B., \& Kar, S. (2021). Stress and coping during covid-19 pandemic: Result of an online survey. Psychiatry Research, 295. https://doi.org/10.1016/j.psychres.2020.113598

Kaya, C., Tansey, T. N., Melekoglu, M., Cakiroglu, O., \& Chan, F. (2019). Psychometric evaluation of Turkish version of the perceived stress scale with Turkish college students. Journal of Mental Health, 28(2), 161-167.

Khalili, R., Ebadi, A., Tavallai, A., \& Habibi, M. (2017). Validity and reliability of the Cohen 10 -item perceived stress scale in patients with chronic headache: Persian version. Asian Journal of Psychiatry, 26, 136-140.

Kirby, R., Shakespeare-Finch, J., \& Palk, G. (2011). Adaptive and maladaptive coping strategies predict posttrauma outcomes in ambulance personnel. Traumatology, 17(4), 25-34.

Lance, C. E., \& Vandenberg, R. J. (2002). Confirmatory factor analysis. In F. Drasgow \& N. Schmitt (Eds.), Measuring and analyzing behavior in organizations: Advances in measurement and data analysis (pp. 221-254). Jossey-Bass.

Lazarus, R. S. (1991). Cognition and motivation in emotion. American Psychologist, 46(4), 352-367.

Lazarus, R. S. (1993). Coping theory and research: Past, present, and future. Psychosomatic Medicine, 55(3), 234-247.

Lazarus, R. S., \& Folkman, S. (1984). Stress, appraisal, and coping. Springer.

Lee, E. H. (2012). Review of the psychometric evidence of the perceived stress scale. Asian Nursing Research, 6(4), 121-127.

Liu, S., Lithopoulos, A., Zhang, C. Q., Garcia-Barrera, M. A., \& Rhodes, R. E. (2021). Personality and perceived stress during COVID19 pandemic: Testing the mediating role of perceived threat and efficacy. Personality and Individual Differences, 168, 110351.

Lyons, M. (1987). A taxonomy of playfulness for use in occupational therapy. Australian Occupational Therapy Journal, 34(4), 152-156.

MacKinnon, D. P., Krull, J. L., \& Lockwood, C. M. (2000). Equivalence of the mediation, confounding and suppression effect. Prevention Science, 1(4), 173-181.

Magnuson, C. D., \& Barnett, L. A. (2013). The playful advantage: How playfulness enhances coping with stress. Leisure Sciences, 35(2), 129-144. https://doi.org/10.1080/01490400.2013.761905

Martocchio, J. J., \& Webster, J. (1992). Effects of feedback and cognitive playfulness on performance in microcomputer software training. Personnel Psychology, 45(3), 553-578.

Maxwell, S. E., \& Cole, D. A. (2007). Bias in cross-sectional analyses of longitudinal mediation. Psychological Methods, 12(1), 23.

Maxwell, S. E., Cole, D. A., \& Mitchell, M. A. (2011). Bias in crosssectional analyses of longitudinal mediation: Partial and complete mediation under an autoregressive model. Multivariate Behavioral Research, 46(5), 816-841.

Mazza, C., Ricci, E., Biondi, S., Colasanti, M., Ferracuti, S., Napoli, C., \& Roma, P. (2020). A nationwide survey of psychological 
distress among Italian people during the COVID-19 pandemic: Immediate psychological responses and associated factors. International Journal of Environmental Research and Public Health, 17(9), 3165. https://doi.org/10.3390/ijerph17093165

McMillan, D. (2017). Towards the playful professional. In Walsh, G., McMillan, D., \& McGuinness, C. (Eds.), Playful Teaching and Learning, 198-212. New York: Sage.

Minahan, J., Falzarano, F., Yazdani, N., \& Siedlecki, K. L. (2021). The COVID-19 pandemic and psychosocial outcomes across age through the stress and coping framework. The Gerontologist, 61(2), 228-239.

Morales-Vives, F., Dueñas, J. M., Vigil-Colet, A., \& Camarero-Figuerola, M. (2020). Psychological variables related to adaptation to the COVID-19 lockdown in Spain. Frontiers in Psychology, 11, 2438.

$\mathrm{Ng}$, S. M. (2013). Validation of the 10-item Chinese perceived stress scale in elderly service workers: One-factor versus two-factor structure. BMC Psychology, 1(1), 1-8.

Ornell, F., Halpern, S. C., Kessler, F. H. P., \& Narvaez, J. C. D. M. (2020). The impact of the COVID-19 pandemic on the mental health of healthcare professionals. Cadernos De Saude Publica, 36, e00063520.

Orsolini, L., Latini, R., Pompili, M., Serafini, G., Volpe, U., Vellante, F., Fornaro, M., Valchera, A., Tomasetti, C., Fraticelli, S., Alessandrini, M., La Rovere, R., Trotta, S., Martinotti, G., Di Giannantonio, M., \& De Berardis, D. (2020). Understanding the Complex of Suicide in Depression: from Research to Clinics. Psychiatry Investigation, 17(3), 207-221. https://doi.org/10.30773/pi.2019. 0171

Örücü, M. Ç., \& Demir, A. (2009). Psychometric evaluation of perceived stress scale for Turkish university students. Stress and Health: Journal of the International Society for the Investigation of Stress, 25(1), 103-110.

Osimo, S. A., Aiello, M., Gentili, C., Ionta, S., \& Cecchetto, C. (2021). The influence of personality, resilience, and alexithymia on mental health during COVID-19 pandemic. Frontiers in Psychology, 12,341 .

Parasuraman, S., \& Hansen, D. (1987). Coping with work stressors in nursing: Effects of adaptive versus maladaptive strategies. Work and Occupations, 14(1), 88-105.

Phua, D. H. (2005). Coping responses of emergency physicians and nurses to the 2003 severe acute respiratory syndrome outbreak. Academic Emergency Medicine, 12(4), 322-328. https://doi.org/ 10.1197/j.aem.2004.11.015

Proyer, R. T. (2012). Development and initial assessment of a short measure for adult playfulness: The SMAP. Personality and Individual Differences, 53(8), 989-994.

Proyer, R. T. (2013). The well-being of playful adults: Adult playfulness, subjective well-being, physical well-being, and the pursuit of enjoyable activities. The European Journal of Humour Research, $1(1), 84-98$.

Proyer, R. T. (2017). A new structural model for the study of adult playfulness: Assessment and exploration of an understudied individual differences variable. Personality and Individual Differences, 108, 113-122. https://doi.org/10.1016/j.paid.2016.12.011

Proyer, R. T., \& Ruch, W. (2011). The virtuousness of adult playfulness: The relation of playfulness with strengths of character. Psychology of Well-Being: Theory, Research and Practice, 1(1), $1-12$.

Proyer, R. T., Gander, F., Bertenshaw, E. J., \& Brauer, K. (2018). The positive relationships of playfulness with indicators of health, activity, and physical fitness. Frontiers in Psychology, 9, 1440.

Qian, X. L., \& Yarnal, C. (2011). The role of playfulness in the leisure stress-coping process among emerging adults: An SEM analysis. Leisure/Loisir, 35(2), 191-209.

Rice, L. (2009). Playful learning. Journal for Education in the Built Environment, 4(2), 94-108.
Richardson, T. M. (2021) Estimated median family income for 2021. U. S. Department of Housing and Urban Development. Retrieved on December 1, 2021 from https://www.huduser.gov/portal/datas ets/il/il21/Medians2021.pdf

Roberti, J. W., Harrington, L. N., \& Storch, E. A. (2006). Further psychometric support for the 10-item version of the perceived stress scale. Journal of College Counseling, 9(2), 135-147.

Rosseel, Y. (2012). Lavaan: An R package for structural equation modeling and more. Version 0.5-12 (BETA). Journal of Statistical Software, 48(2), 1-36.

Rossi, R., Socci, V., Pacitti, F., Di Lorenzo, G., Di Marco, A., Siracusano, A., \& Rossi, A. (2020). Mental health outcomes among frontline and second-line health care workers during the coronavirus disease 2019 (COVID-19) pandemic in Italy. JAMA Network Open, 3(5), e2010185-e2010185.

Salari, N., Hosseinian-Far, A., Jalali, R., Vaisi-Raygani, A., Rasoulpoor, S., Mohammadi, M., ... Khaledi-Paveh, B. (2020). Prevalence of stress, anxiety, depression among the general population during the COVID-19 pandemic: A systematic review and metaanalysis. Globalization and Health, 16(1), 1-11.

Saunders, I., Sayer, M., \& Goodale, A. (1999). The relationship between playfulness and coping in preschool children: A pilot study. American Journal of Occupational Therapy, 53(2), 221226. https://doi.org/10.5014/ajot.53.2.221

Shen, X. S., Chick, G., \& Zinn, H. (2014). Adult playfulness trait scale. PsycTESTS Dataset. https://doi.org/10.1037/t61751-000

Staempfli, M. B. (2007). Adolescent playfulness, stress perception, coping, and well-being. Journal of Leisure Research, 39(3), 393-412.

Sutton-Smith, B. (1966). Piaget on play: A critique. Psychological review, 73(1), 104.

Tanis, D. J. (2012). Exploring play/playfulness and learning in the adult and higher education classroom. The Pennsylvania State University.

Teasdale, E., Yardley, L., Schlotz, W., \& Michie, S. (2012). The importance of coping appraisal in behavioural responses to pandemic flu. British Journal of Health Psychology, 17(1), 44-59. https:// doi.org/10.1111/j.2044-8287.2011.02017.x

Tegano, D. (1990). Relationship of tolerance of ambiguity and playfulness to creativity. Psychological Reports, 66(3), 1047-1056.

Wang, C., Pan, R., Wan, X., Tan, Y., Xu, L., McIntyre, R. S., Choo, F. N., Tran, B., Ho, R., Sharma, V. K., \& Ho, C. (2020). A longitudinal study on the mental health of general population during the COVID-19 epidemic in China. Brain, Behavior, and Immunity, 87, 40-48. https://doi.org/10.1016/j.bbi.2020.04.028

World Health Organization. (n.d.). who coronavirus (COVID-19) dashboard. World Health Organization. Retrieved December 19, 2021 , from https://covid19.who.int/.

World Health Organization. (2020). WHO Director-General's Remarks at the Media Briefing 11 March 2020. Retrievied August 2021 from https://www.who.int/director-general/speeches/detail/ who-director-general-s-opening-remarks-at-the-media-brief ing-on-covid-19---11-march-2020.

Young, N. A., Waugh, C. E., Minton, A. R., Charles, S. T., Haase, C. M., \& Mikels, J. A. (2021). Reactive, agentic, apathetic, or challenged? Aging, emotion, and coping during the COVID-19 pandemic. The Gerontologist, 61(2), 217-227.

Zalsman, G., Stanley, B., Szanto, K., Clarke, D. E., Carli, V., \& Mehlum, L. (2020). Suicide in the time of COVID-19: Review and recommendations. Archives of Suicide Research, 24(4), 477-482.

Publisher's Note Springer Nature remains neutral with regard to jurisdictional claims in published maps and institutional affiliations. 